\title{
Polyplax guatemalensis sp. n. (Phthiraptera: Anoplura), a new sucking louse from Peromyscus grandis, a montane cloud forest rodent from Guatemala
}

\author{
Lance A. Durden ${ }^{1}$ and Ralph P. Eckerlin ${ }^{2}$
}

${ }^{1}$ Institute of Arthropodology and Parasitology, Georgia Southern University, P.O. Box 8056, Statesboro, Georgia 30460, USA;

${ }^{2}$ Natural Sciences Division, Northern Virginia Community College - Annandale Campus, 8333 Little River Turnpike, Annandale, Virginia 22003, USA

Key words: Phthiraptera, Anoplura, sucking louse, new species, Guatemala, Polyplax guatemalensis, Peromyscus grandis

\begin{abstract}
The adult male and female of Polyplax guatemalensis sp. n. are described from the sigmodontine murid rodent Peromyscus grandis Goodwin collected in the Reserva de Biosfera, Sierra de las Minas, Guatemala, at an elevation of 2,200 m. The new species extends the number of known native species of Polyplax in the New World to four with none of them recorded south of Panama. Polyplax guatemalensis is morphologically most closely related to Polyplax auricularis which parasitises a cluster of closely related New World sigmodontine rodents from Canada to Panama. These two species can be distinguished from all other known species of Polyplax by the presence of partially overlapping, subtriangular, anterior abdominal plates in both sexes. Polyplax guatemalensis can be separated from $P$. auricularis by the abundant tergal abdominal setae and longer pseudopenis in males, and by the presence of one fewer anterior abdominal, subtriangular tergite and sternite in females.
\end{abstract}

The sucking louse genus Polyplax Enderlein, 1904 is well represented in the Old World where 76 native species have been recorded (Durden and Musser 1994, Chin 1995) but poorly represented in the New World where, until now, just three native species have been recorded (Durden and Webb 1999). In addition to the three native New World species, Polyplax serrata (Burmeister, 1839) and Polyplax spinulosa (Burmeister, 1839) have accompanied introduced commensal mice and rats, respectively, and are now widespread in this region as they are throughout much of the world. Recently, one of us (RPE) was part of a field team that collected and inventoried small mammals and their ectoparasites in Guatemala. During this survey, a new species of Polyplax was collected from an endemic Central American sigmodontine murid rodent. The new louse is described and illustrated in this paper.

\section{MATERIALS AND METHODS}

The descriptive format followed in this paper is that of Durden and Webb (1999) which was based on that of Kim and Ludwig (1978). Names and abbreviations for setae follow those two papers and are spelled out in full when first mentioned in this paper. All louse specimens were cleared in $10 \%$ potassium hydroxide, dehydrated through a series of ethanol washes of ascending concentration, further cleared in xylene, and then slide-mounted in Canada balsam following standard procedures (Kim et al. 1986). Specimens were measured with a calibrated eyepiece graticule fitted into a high-power Olympus BH-2 light microscope. Drawings were prepared with the aid of a Leitz PRADO 500 microprojector.

\section{RESULTS}

Family P o 1 y p 1 a c i d a e Fahrenholz, 1912

Polyplax guatemalensis sp. $\mathrm{n}$.

Figs. 1-8

Male Figs. 1-4 (35 specimens): Length of holotype $1.325 \mathrm{~mm}$; range $1.300-1.525 \mathrm{~mm}$; mean $1.396 \mathrm{~mm}$. Head, thorax and abdomen moderately sclerotised.

Head slightly longer than wide, relatively blunt anteriorly with anterolateral lobe on each side; 1 dorsal anterior head seta (DAnHS), 2 dorsal preantennal head setae (DPaHS), 1 supraantennal head seta (SpAtHS), 1 sutural head seta (SuHS), 1 dorsal marginal head seta (DMHS), 1 dorsal posterior central head seta (DPoCHS), 1 relatively long dorsal principal head seta (DPHS), 1 short dorsal accessory head seta (DAcHS), 1 apical head seta (ApHS), 2 anterior marginal head setae (AnMHS), 2 ventral preantennal head setae (VPaHS) and 1 stout ventral principal head seta (VPHS) on each side. Antennae 5-segmented with basal segment much larger than other segments, slightly wider than long; third antennal segment modified with anterodorsal projection.

Thorax longer than broad with margins tapering anteriorly; thoracic sternal plate (Fig. 2) shield-shaped but with concave edges especially apparent anteriorly and posteriorly; mesothoracic spiracle diameter $0.024 \mathrm{~mm}$; dorsal principal thoracic setae (DPTS) moderate in length $(0.14 \mathrm{~mm})$; no other thoracic setae present except on legs. Legs with subtriangular coxae; forelegs small with narrow acuminate claw; mid- and hindlegs progressively larger each with correspondingly larger acuminate claw. 

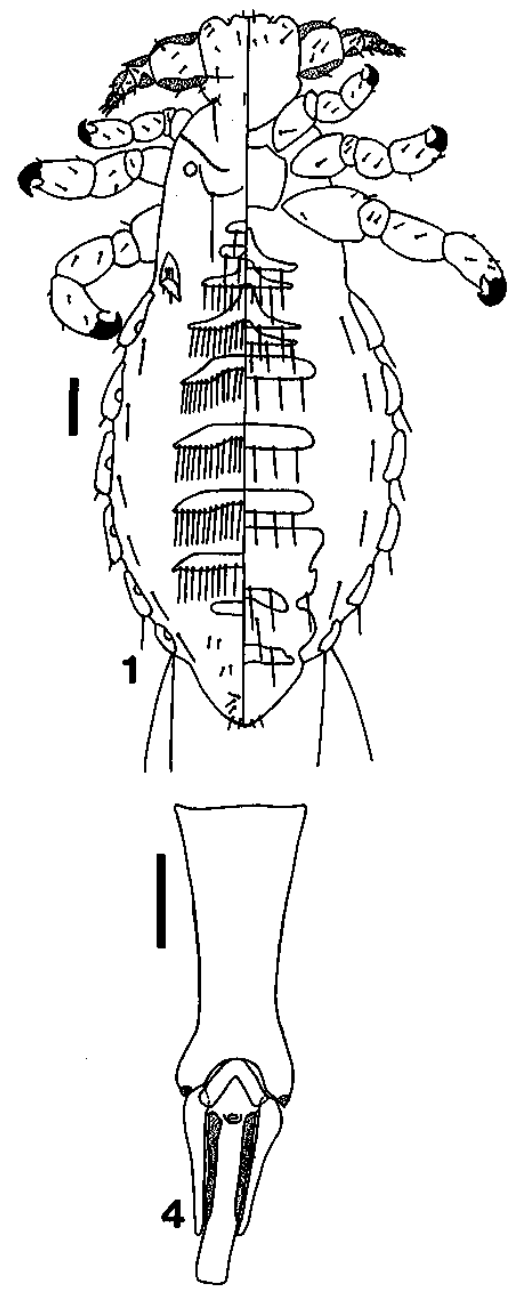
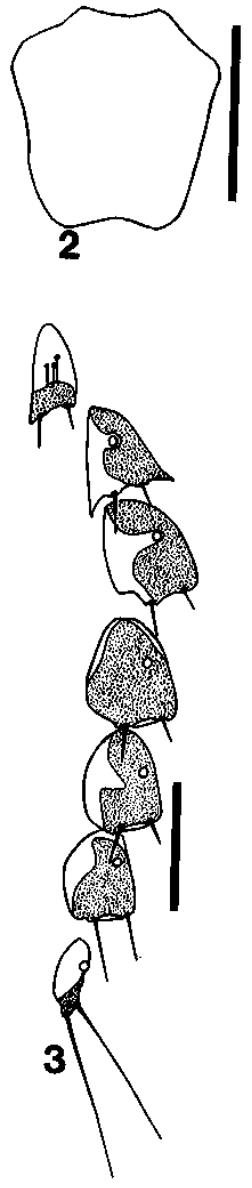

Figs. 1-4. Polyplax guatemalensis sp. n., male. Fig. 1. Entire body; ventral morphology to right of midline, dorsal features on left. Fig. 2. Thoracic sternal plate. Fig. 3. Paratergal plates. Fig. 4. Genitalia. All scale bars $=0.1 \mathrm{~mm}$.

Abdomen wider than thorax; 1 sternite ventrally on each of segments 1-2 and 4-6; 2 sternites on segment 3; sternites 1-4 subtriangular; anterior apices of sternites 2-4 each partially overlapping preceding sternite medially; sternites 5-7 subrectangular but with rounded lateral margins; sternites 1-3 each with 4 sternal abdominal setae (StAS); 2 short central StAS on sternite 2; sternites 4-7 each with 6 StAS. One ventral lateral abdominal seta (VLAS) on each side on segments 3-7. One tergite dorsally on each of segments 1 and $3-8 ; 2$ tergites on segment 2; tergites 1, 2 and 9 small and subrectangular but with rounded lateral margins; tergites 3 and 4 subtriangular; tergites 5-8 each with distal sections directed posteriorly to varying degrees; tergite 1 with 2 tergal abdominal setae (TeAS); tergite 2 with 4 TeAS; tergite 3 with 12 TeAS; tergites 4-8 each with 18-24

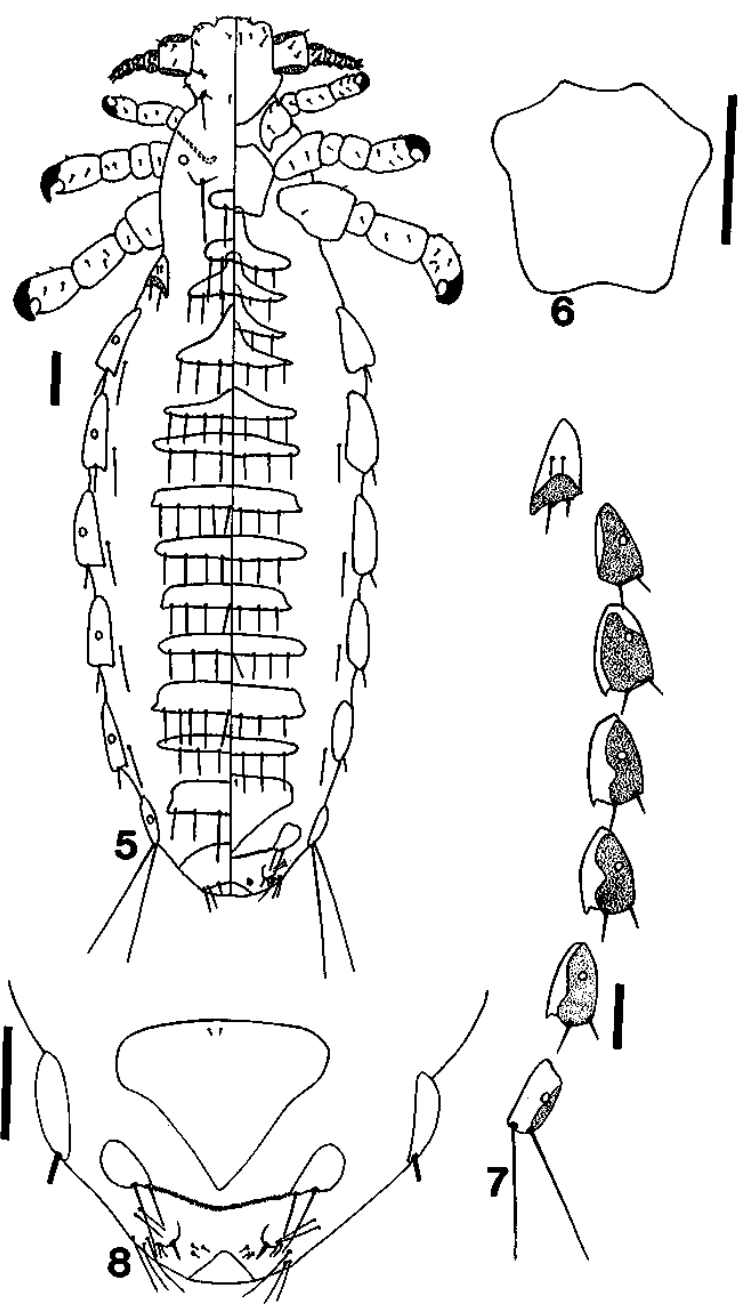

Figs. 5-8. Polyplax guatemalensis sp. n., female. Fig. 5. Entire body; ventral morphology to right of midline, dorsal features on left. Fig. 6. Thoracic sternal plate. Fig. 7. Paratergal plates. Fig. 8. Genitalia. All scale bars $=0.1 \mathrm{~mm}$.

TeAS; tergite 9 lacking setae. One dorsal lateral abdominal seta (DLAS) on each side on segments 3-8. Paratergal plates (Fig. 3) present on segments 2-8; plates I-VI all subtriangular with 2 apical setae of moderate length and with ventral seta always slightly longer than dorsal seta on same plate; plate I also with 2-3 (usually 3 ) central setae; plate VII with 2 long apical setae; all plates differentially sclerotised as shown (Fig. 3); plates II-VII each with moderately sized spiracle.

Genitalia (Fig. 4) with basal apodeme about twice as long as parameres; parameres tapering posteriorly; pseudopenis long, extending well beyond apex of parameres, with blunt posterior apex; basal apodeme heavily sclerotised in 2 small posterolateral regions and pseudopenis heavily sclerotised along anterolateral margins as shown in Fig. 4. Subgenital plate (shown in 
Fig. 1) extending anteriorly to abdominal segment 6 , with relatively straight anterior margin, jagged lateral margins, 2 wide central lacunae and 10 relatively long setae positioned as shown in Fig. 1.

Female Figs. 5-8 (41 specimens): Length of allotype $1.725 \mathrm{~mm}$; range $1.575-1.950 \mathrm{~mm}$; mean $1.782 \mathrm{~mm}$. Head, thorax and abdomen as in male unless indicated otherwise.

Head with third antennal segment unmodified.

Thorax with lateral margins slightly more concave on thoracic sternal plate (Fig. 6) than in male.

Abdomen with 1 sternite on each of segments 1 and 2; 2 sternites on each of segments 3-7; sternites 1-5 subtriangular; anterior apices of sternite 1 partially overlapping posterior margin of thoracic sternal plate; anterior margins of sternites 2-4 partially overlapping posterior edge of preceding sternite medially; sternites 612 subrectangular but with either rounded or partially emarginate lateral margins; sternites 1-3 each with 4 StAS; 2 short central StAS on sternite 2; sternites 4-12 each with 6-7 StAS; StAS on sternite 12 longer than StAS on other sternites. One VLAS on each side on segments 4-7. One tergite dorsally on each of segments 1,3 and $8 ; 2$ tergites on each of segments 2 and 4-7; tergites $1-2$ and 6-13 each subrectangular but with either rounded or partially acuminate lateral margins; anterior apex of tergite 3 partially overlapping posterior margin of tergite 2 medially; tergite 1 with 2 relatively long TeAS; tergite 2 with 4 relatively long TeAS; tergites 3-12 each with 6-9 TeAS of moderate length; tergite 13 with 6 TeAS including 2 long central TeAS. One DLAS on each side on segments 3-7. Paratergal plates (Fig. 7) similar to those of male but exact shapes and regions of heavier sclerotisation as shown in Fig. 7, and plate I with 2-3 (usually 2) central setae.

Genitalia (Fig. 8). Subgenital plate subtriangular with 2 small setae anteriorly and poorly sclerotised posteriorly; gonopods VIII subtriangular, each with 2 posteromedially directed setae of subequal length; gonopods IX each with 1 stout posteromedially directed seta; vulvar fimbriae distinct.

$\mathrm{T}$ y p e h o s t : Holotype male and allotype female from male Peromyscus grandis Goodwin, 1932 (Rodentia, Muridae, Sigmodontinae); host field number, MANCA 449; type host deposited in the Carnegie Museum of Natural History, Pittsburgh, USA (catalogue No. CM113426). Paratypes collected from the type host and from different $P$. grandis individuals from the same locality by the same collectors (see below) on various dates during April 1998.

T y p e 1 o c a 1 i t y : 6 km NNW of San Lorenzo, Zacapa, Rio Hondo, Reserva de Biosfera, Sierra de las Minas, Guatemala, at 2,200 m elevation in primary montane cloud forest; 9 April 1998; collector: R.P. Eckerlin.

E t y m o l o g y: The specific epithet of the new taxon reflects the country in which it was collected.

D e p o s it i o n of ty pe s : Holotype ( $\left.\sigma^{\Uparrow}\right)$, allotype (q) and 51 paratypes $(23 \hat{\partial}, 28+$ ) in the U.S. National Museum of Natural History, Smithsonian Institution, Washington, D.C.,
USA. Additional paratypes deposited in the Museo de Historia Natural, Universidad de San Carlos de Guatemala, Guatemala City $(2 \hat{\jmath}, 2$ + $)$; Natural History Museum, London, UK $\left(3 \lambda^{\lambda}, 3\right.$ ㅇ); Carnegie Museum of Natural History, Pittsburgh, USA $(1 \hat{\jmath}, 1$ 우); Institute of Parasitology, Academy of

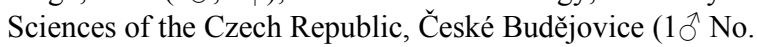
PAU AVČR 1982 and 19 No. PAU AVČR 1983) and the collections of the authors $(4 \hat{O}, 4$ $)$.

\section{DISCUSSION}

The new species described here is a typical member of the genus Polyplax and has clear morphological affinities with another New World species, Polyplax auricularis Kellogg et Ferris, 1915, which parasitises New World sigmodontine rodents (Peromyscus Gloger, Onychomys Baird and Reithrodontomys Giglioli spp.) from Canada south to Panama (Durden and Musser 1994). The morphological attributes shared by $P$. auricularis and $P$. guatemalensis include the subtriangular shape and partially overlapping nature of the anterior abdominal plates, the shape of the thoracic sternal plate, and the general shape and degree of sclerotisation of the paratergal plates. The shape of the female subgenital plates and that of the male basal apodemes and parameres are also similar in both species. The presence of partially overlapping anterior abdominal plates distinguishes both $P$. auricularis and $P$. guatemalensis from other known species of Polyplax. Nevertheless, these two species are easily separated. Males are readily distinguished by the abundant tergal abdominal setae (TeAS) and pseudopenis extending well beyond the apices of the parameres in P. guatemalensis compared to sparse TeAS and pseudopenis extending to about the level of the paramere apices in P. auricularis. Females can be separated most easily by determining the number of subtriangular sternites (6 in $P$. auricularis, 5 in $P$. guatemalensis) or tergites (4 in $P$. auricularis, 3 in $P$. guatemalensis), the setation of gonopods VIII (1 long and 2 short setae in $P$. auricularis, 2 setae of intermediate length in $P$. guatemalensis) or the number on small setae inserted anteriorly on the subgenital plate (4 in $P$. auricularis, 2 in P. guatemalensis).

Although the sucking louse genus Polyplax is diverse with 80 described species worldwide, until now, only 3 native species were known from the New World. This largely relates to the zoogeographical origin of this genus of rodent-associated lice in the Old World (Traub 1980, Durden and Traub 1990). However, a small number of Polyplax spp. lice clearly were able to successfully colonise the New World as ectoparasites of sigmodontine and arvicoline murid rodents as evidenced by the three previously documented native species and the fourth species which is described in this paper. None of these lice has been reported south of Panama, where North and South America remained separated before the two continents were joined along the southern Central American isthmus 2.5-3 million years ago (Vrba 1992). This strongly implies that Polyplax has colonised the New 
World relatively recently from the north presumably via Beringian connections as lice accompanied migrating rodents of Palaearctic origin. In fact, Polyplax borealis Ferris, 1933 is now widely distributed throughout both the northern Palaearctic and Nearctic regions as a parasite of several species of arvicoline rodents (voles). The remaining two native New World species of Polyplax are P. auricularis which has already been discussed, and $P$. alaskensis Ewing, 1927 which is a parasite of North American lemmings and voles as far south as Mexico (Durden and Musser 1994). We believe that one or more as yet undescribed species of Polyplax may parasitise native Central American rodents. However, because of the northern origin and colonisation route of Polyplax into the New World, it is unlikely that native Polyplax species will be recorded south of Panama (Durden and Webb 1999).
Acknowledgements. We thank T.J. McCarthy (Carnegie Museum of Natural History, Pittsburgh, USA) for identifying rodent hosts. Field assistance was provided by J. O. Matson, T.J. McCarthy, N. Ordóñez, and S.G. Pérez. Consejo Nacional de Areas Protegidas (CONAP) and Defensores de la Naturaleza provided collecting permits for the Sierra de las Minas Preserve. Financial support was provided by the National Geographic Society (Grant No. 6105-98 to T.J. McCarthy), U.S. Food and Drug Administration Produce Safety Initiative (to R.P. Eckerlin), and the Cecil Shuler Open Moment Fellowship from the Northern Virginia Community College Educational Foundation (to R.P. Eckerlin). For the use of equipment, storage space, and other courtesies, we are indebted to personnel in the Section of Mammals, Carnegie Museum of Natural History, and the Museo de Historia Natural, Universidad de San Carlos de Guatemala. This paper is a contribution from Mastozoologia en el Núcleo de Centro America (MANCA).

\section{REFERENCES}

CHIN T.-H. 1995: A new species of sucking louse from Cricetulus longicaudatus Milne-Edwards. Acta Zootaxonom. Sin. 20: 97-101.

DURDEN L.A., MUSSER G.G. 1994: The sucking lice (Insecta, Anoplura) of the world: a taxonomic checklist with records of mammalian hosts and geographical distributions. Bull. Am. Mus. Nat. Hist. 218: 1-90.

DURDEN L.A., TRAUB R. 1990: Zoogeographical implications from rodent ectoparasites in Sulawesi. In: W.J. Knight and J.D. Holloway (Eds.), Insects and the Rain Forests of South East Asia (Wallacea). Royal Entomological Society, London, pp. 57-62.

DURDEN L.A., WEBB J.P. 1999: Abrocomaphthirus hoplai, a new genus and species of sucking louse from Chile and its relevance to zoogeography. Med. Vet. Entomol. 13: 447452.

KIM K.C., LUDWIG H.W. 1978: The family classification of the Anoplura. Syst. Entomol. 3: 249-284.

KIM K.C., PRATT H.D., STOJANOVICH C.J. 1986: The Sucking Lice of North America: An Illustrated Manual for Identification. The Pennsylvania State University Press, University Park, Pennsylvania, 241 pp.

TRAUB R. 1980: The zoogeography and evolution of some fleas, lice and mammals. In: R. Traub and H. Starcke (Eds.), Fleas: Proceedings of the international conference on fleas. A.A. Balkema, Rotterdam, pp. 93-172.

VRBA E.S. 1992: Mammals as a key to evolutionary theory. J. Mammal. 73: 1-28. 